\title{
Labour costs
}

\section{Office for National Statistics}

\section{SUMMARY}

Labour costs cover all aspects of costs incurred by employers when employing workers. These include wages and salaries, National Insurance and social contributions, redundancy payments, benefits in kind, overheads and other nonwage components.

This article gives a brief overview of the structure of labour costs and then focuses on earnings (the largest component of labour costs). It shows how earnings in the whole economy have changed over time and also the earnings distribution by occupation. The other topics of interest analysed in the article are the gender pay gap both over time and by various personal characteristics, as well as estimates of how many people are paid below the National Minimum Wage. abour costs and the distribution of pay straddle both labour demand and labour supply within the labour market framework. From the demand side, labour is a necessary factor of production: firms need people to make their output, which they will trade with consumers.

From the supply side, people choose to trade their time in order to increase their real income, in order to buy the goods and services that others produce. In other words, people choose to work so that they are paid. If there is a shortage of people with the required skills to do the work then a firm will have to increase wages to attract workers. Conversely, if there is an increase in the size of the available labour force, wages can be decreased as there is a larger supply of labour and more competition for jobs. These are the dynamics of labour supply, labour demand and labour costs, represented at the most simplistic level.

\section{Labour costs}

Labour costs are the whole range of costs employers incur when employing workers. They include wages and salaries, National Insurance and social contributions, redundancy payments, benefits in kind, overheads and other non-wage components. On the labour demand side, an employer has to consider all these costs in assessing the impact on the business of recruiting and employing staff.

Figure 1 shows that by far the largest component of labour costs is wages and salaries, which makes up four-fifths of the total.

On the supply side, the disposable income of an individual is made up of wages and salaries, occupational pensions, investments, non-government sources and government sources (cash benefits), less any direct taxes, National Insurance contributions and council tax. All of these sources of income influence

\section{Figure 1}

The structure of labour costs, 2004

United Kingdom

Percentages Other labour costs $(2 \%)$

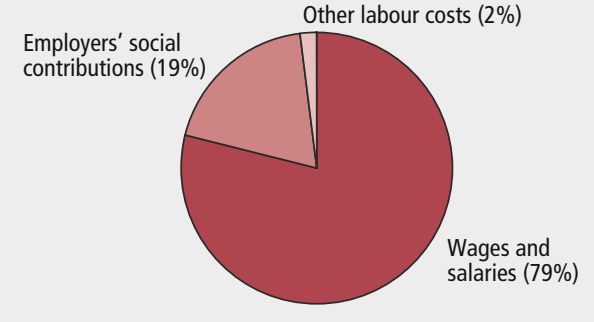

Source: Labour Cost Survey, 2004 
Figure 2

\section{AEI whole economy growth rate (including bonuses), year-on-year growth of the RPI (all items) and derived real earnings growth ${ }^{1}$}

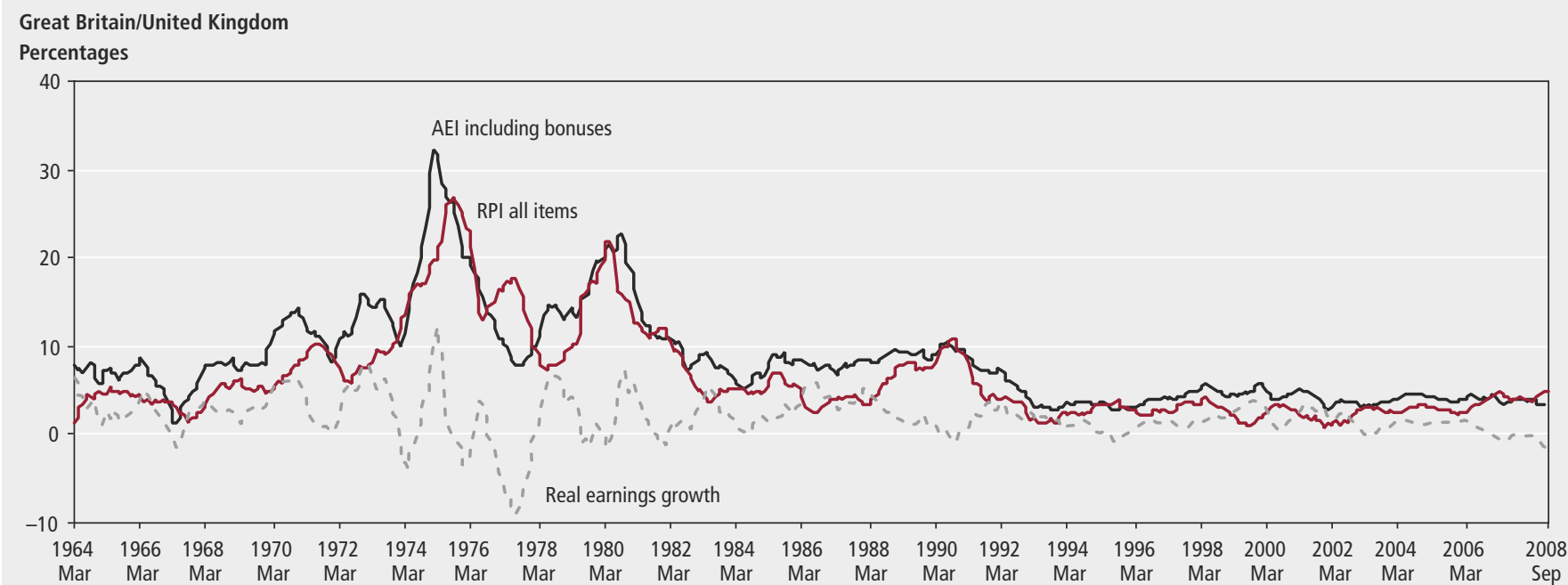

Note:

Source: Average Earnings Index, Retail Price Index

1 The AEI covers Great Britain and the RPI covers the United Kingdom.

an individual's decision to supply their labour.

Analysis of labour costs and distribution is limited by the availability of relevant information. For this reason, the Office for National Statistics (ONS) mainly focuses on earnings (wages and salaries), the largest and most important component of labour cost and the most collected, in the majority of its analyses.

\section{Earnings}

The growth in whole economy earnings is measured by the Average Earnings Index (AEI), which uses a fixed distribution of employees to monitor change from one period to the next. The AEI 'including bonus series' shows that earnings rose by 3.3 per cent in the year to September 2008, which is a slower rate of growth than in previous years. This was the slowest rate of increase since mid-2003. It was also much slower than the growth observed in the 1970s, 1980s and early 1990s.

Although the annual growth figure for September is an 'including' bonus figure, it will be less affected by growth in bonuses, because it falls outside the season when most bonuses are paid - which runs from December to April. Compared with September, earnings growth during the bonus season has tended to be higher in recent years: for example, in March 2008 it was 4.0 per cent, and in March 2007 it was 4.3 per cent. ONS also publishes an excluding bonus series which has remained steady over the last couple of years, despite an increasing Retail Prices Index (RPI). The excluding bonus series increased by
3.6 per cent in the year to September 2008 compared with an increase of 3.7 per cent in the year to September 2007. Either measure shows that the overall picture is of steady growth in earnings.

Growth in average earnings can be compared with growth in the price of goods, to help understand real earnings growth. This is more indicative of the purchasing power of earnings. In other words, it indicates whether the growth in earnings allows people to purchase more, or if the cost of goods has also gone up.

Figure 2 displays the real earnings growth, calculated from AEI earnings growth (including bonuses) minus the all items RPI, an indicator of domestic inflation. In September 2008, the annual rate of increase in the all items RPI was 5.0 per cent, which was above earnings growth, implying a fall in real earnings of 1.7 per cent in the year to September 2008. Real

\section{Figure 3}

\section{Average weekly earnings in the whole economy}

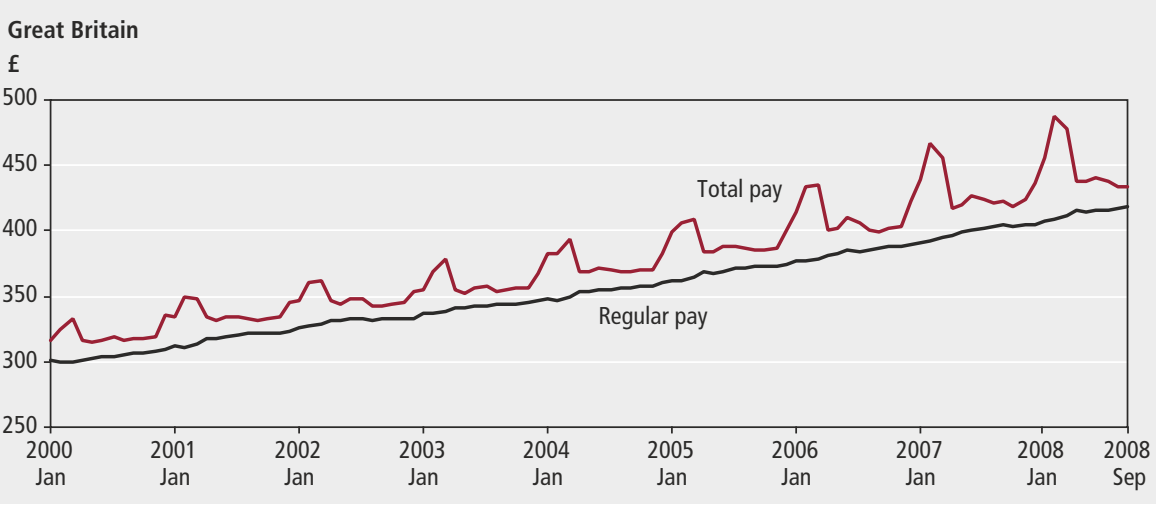

Source: Average Weekly Earnings 
Figure 4

\section{Year-on-year growth rates of public and private sector earnings (including bonuses)}

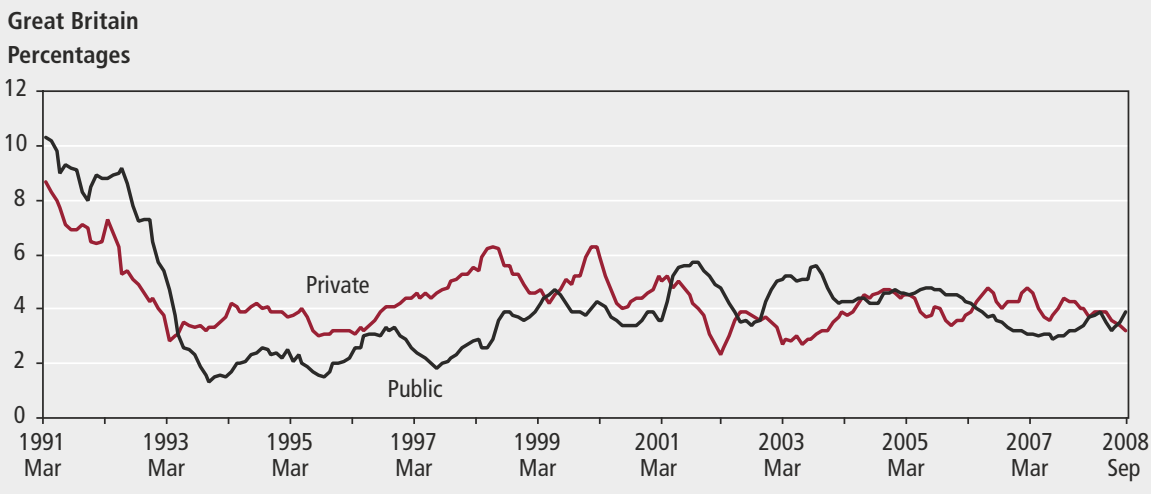

Source: Average Earnings Index

\section{Figure 5}

\section{Year-on-year growth rates in the manufacturing and services sectors (including bonuses)}

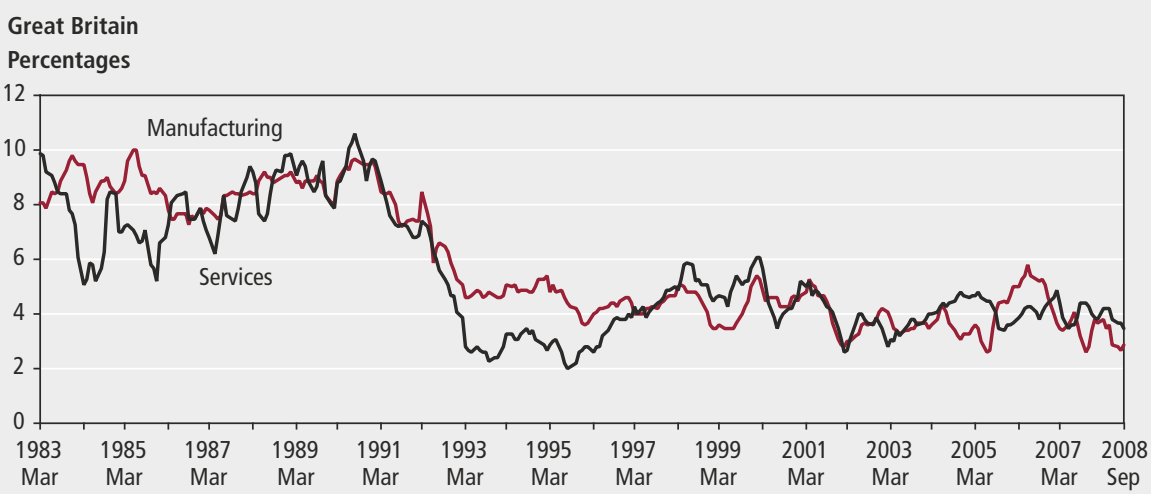

Source: Average Earnings Index

Figure 6

Bonus payments for the financial sector and whole economy ${ }^{1}$

\section{Great Britain \\ $\mathrm{f}$ billion}

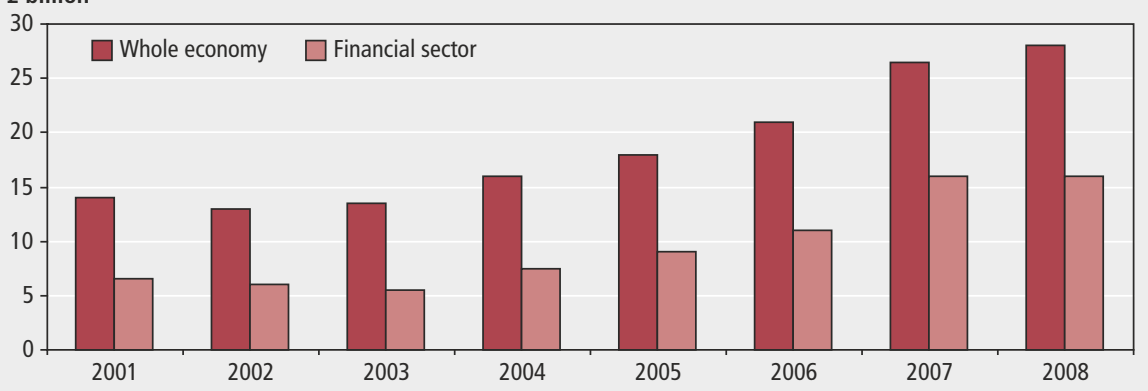

Note:

Source: Average Weekly Earnings

1 The figures are derived from the experimental Average Weekly Earnings series. All data relate to the period December of the previous year to April in the current year: for example, 2008 relates to the period December 2007 to April 2008.

Using the AEI and looking at earnings growth by sector in the year to September 2008, the private sector earnings growth (including bonuses) was 3.2 per cent compared with public sector earnings growth of 3.9 per cent (Figure 4).

In the year to September 2008, earnings (including bonuses) in the manufacturing sector grew by 2.9 per cent, which represents a decrease in growth since a recent high of 4.1 per cent in the year to July 2007 (Figure 5). In the year to September 2008, earnings in the services sector increased by 3.5 per cent, which is a deceleration of growth since the most recent peak of 4.2 per cent in the year to May 2008.

\section{Bonus growth}

Bonus payments are a major influence on pay growth. Changes in their level or the month in which they are paid can have a significant effect on growth rates for the economy. Bonus payments across the whole economy doubled from about $£ 14$ billion to about $£ 28$ billion over the period 2001 to 2008 (Figure 6). Over the same period, payments in the financial sector grew from $£ 6.5$ billion to $£ 16$ billion. Growth in the financial sector therefore contributed about two-thirds of the growth in the whole economy.

For the latest year, bonus payments across the whole economy amounted to about $£ 28$ billion in the period December 2007 to April 2008, up $£ 1.5$ billion on the same period a year earlier. Payments in the financial sector amounted to $£ 16$ billion, unchanged on a year earlier.

\section{Non-wage costs}

The experimental Index of Labour Costs per Hour (ILCH) provides a timely indicator of changes in the cost of labour per hours worked. It reflects the changes in wages and salaries, non-wage costs and the quantity of hours worked over time. This measure assists in the analysis of inflationary pressures originating from the labour market which result from changes in total labour costs per hour. It can be used alongside other earnings indicators (such as the AEI or the AWE, both covered earlier) to see how the movement of nonwage costs affect the overall cost of labour. The non-wage costs included in the index are sickness, maternity and paternity costs, pension contributions, benefits in kind and National Insurance contributions.

The ILCH is more sensitive to movements in employment patterns throughout the year than other measures of earnings (Figure 7). The main difference is in the third quarter of the year, where the ILCH has higher growth. Fewer hours are worked in the summer months and wages stay broadly constant, so the relative cost of labour increases. This effect is removed when the index is seasonally adjusted.

The year-on-year growth rate of total labour costs fell to 2.5 per cent in 2008 Q3. The last time it was lower was three years earlier, in 2005. The growth rate in total other costs reached the lowest it had been since the series began in 2001, with a growth rate of 0.9 per cent in 2008 Q3. The very high growth rate for total other costs 


\section{Figure 7}

\section{Year-on-year growth rates of total labour costs, total wage costs and total other costs}

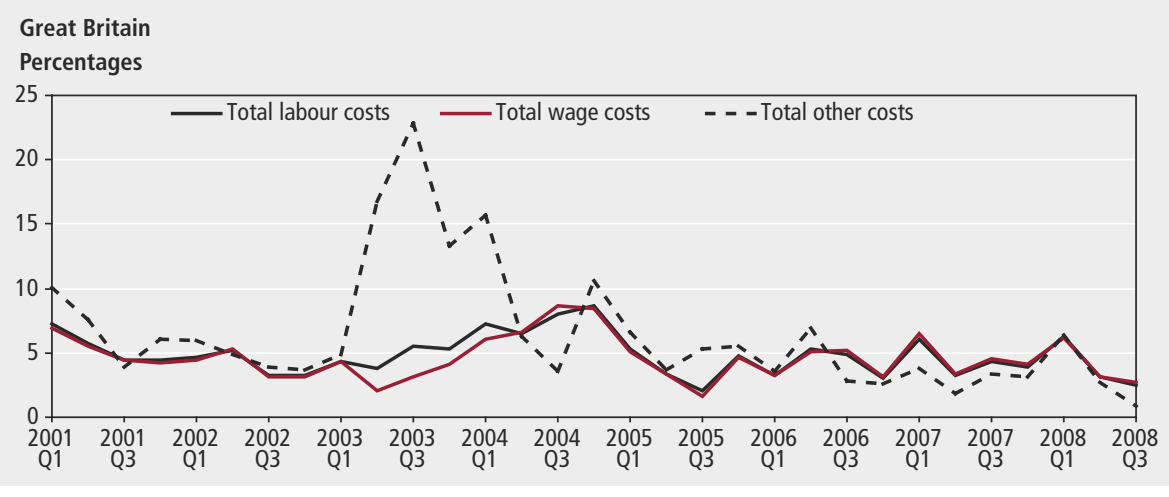

Source: Index of Labour Costs per Hour shown for 2003 Q2 can be explained by the significant increase in National Insurance contributions.

\section{Earnings distribution}

Information on earnings is available from the Annual Survey of Hours and Earnings (ASHE), along with a number of employee measure of growth in earnings but ASHE is used to look at the distribution of earnings.

According to ASHE, the median gross weekly pay for full-time employees in the UK grew to $£ 479$ in 2008 . The median is the middle point of a population with exactly the same number of data values above and below. It is a better way of comparing the levels of earnings than the mean as it is less influenced by extreme values at the top end of the pay distribution. The median gross hourly earnings of full-time employees grew to $£ 11.87$ in 2008 , up by 4.5 per cent on 2007. This is based on adults who worked full time and whose pay was unaffected by absence and excludes overtime.

The overall growth in earnings has led to noticeable changes in the rate of growth for the highest and lowest earners in 2008 compared with the previous year. Full-time employees in the bottom 10 per cent earned less than $£ 262$ a week (including overtime) in 2008, 3.5 per cent higher than in 2007.

Full-time adults in the top 10 per cent earned more than $£ 947$ a week (including overtime), 4.4 per cent higher than in 2007. Figure 8 shows the ratio of the amount the top 10 per cent earned compared with the amount the bottom 10 per cent earned (the $90 / 10$ ratio). In 2008 , the weekly amount the top 10 per cent earned was 3.62 times higher than the amount the bottom 10 per cent earned; in 2007 it was 3.59 and in 1998 it was 3.52.

Figure 9 shows the levels of earnings in 2008 by occupation, compared with the UK average. It presents comparisons of the characteristics. The AEI is the preferred median levels of gross weekly earnings for full-time employees whose pay was not affected by absence. In 2008, the median 'managers and senior officials' occupation group had the highest median pay in 2008

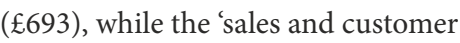
service’ occupations had the lowest (£287). gross weekly pay for the UK was $£ 479$. The

\section{Gender pay gap}

The gender pay gap is a measure of the difference between the earnings of men and women. It is determined by calculating women's average pay as a percentage of men's. The pay gap is the difference between this and 100 per cent. So, for example, the gender pay gap is 15 per cent if women's pay is 85 per cent of men's pay.

There are various ways to measure the gender pay gap, for example, using the median or mean earnings of men and women in the calculation. ONS focuses on the median rather than the mean, for the reason mentioned previously. Although median hourly pay provides a useful comparison between the earnings of men and women, it does not necessarily indicate differences in rates of pay for comparable jobs. Average pay is affected by the different work patterns of men and women, such as the proportions in different occupations and their length of time in jobs. These differences may also be attributed to gender factors, for example,

\section{Figure 8 \\ Ratio of the 90th to the 10th percentile of gross median weekly earnings of full-time employees}

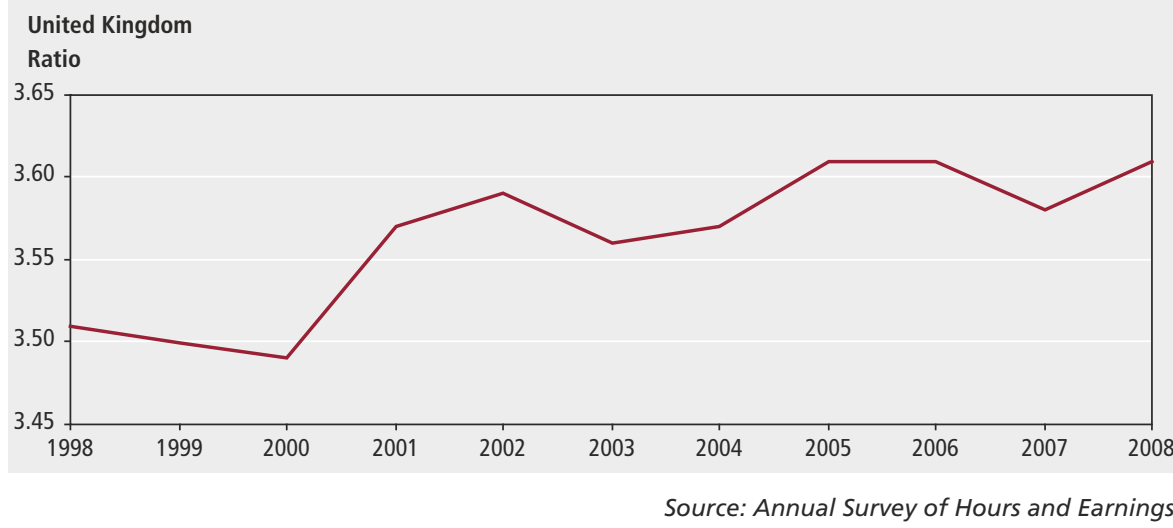

Figure 9

Percentage difference from average gross weekly pay for full-time employees: by occupation, 2008

United Kingdom

Percentages

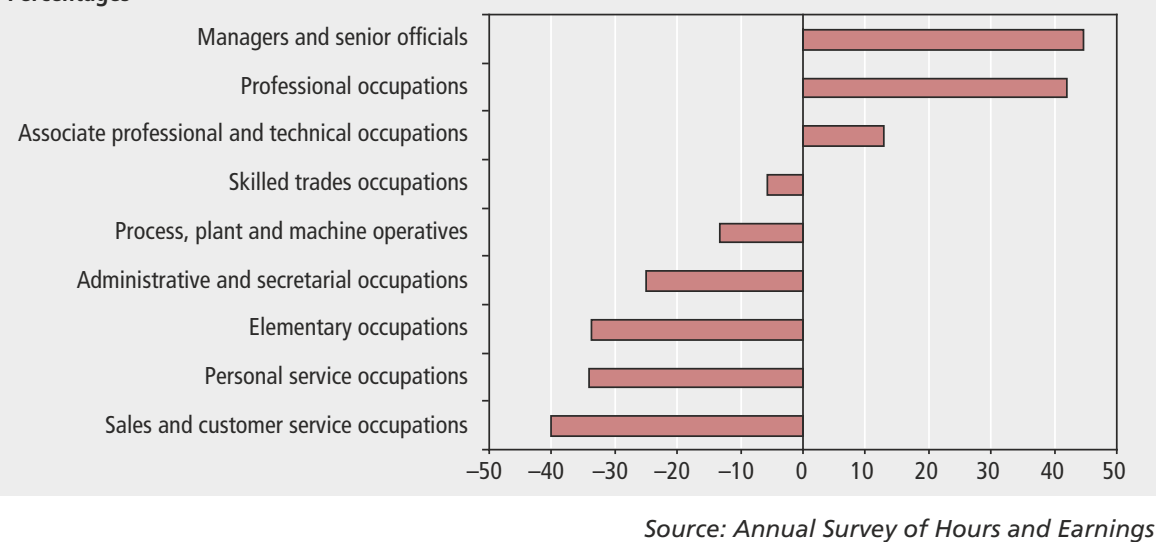


Figure 10

\section{Gender pay gap of full-time employees ${ }^{1,2}$}

United Kingdom

Percentages

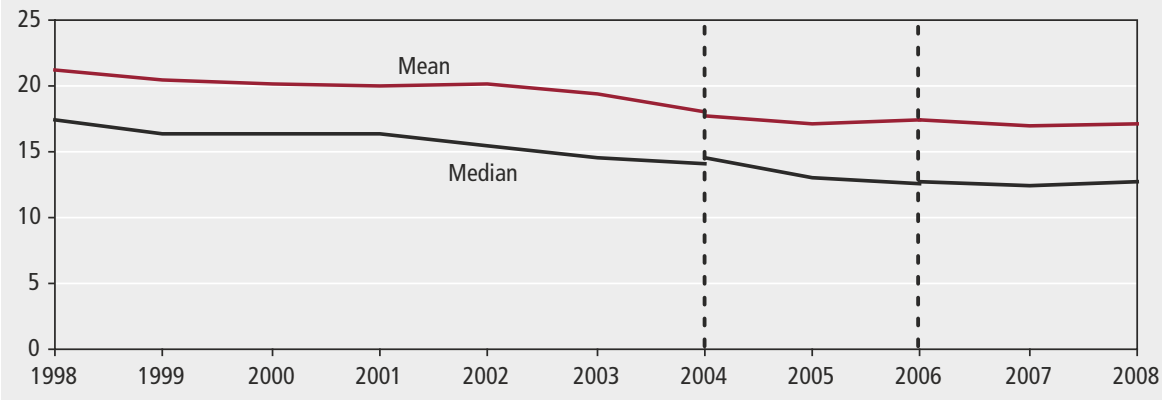

Notes:

Source: Annual Survey of Hours and Earnings

1 Includes those on adult rates of pay, excluding overtime and unaffected by absence.

2 ASHE was introduced in 2004, replacing the New Earnings Survey by implementing a new imputation and weighting methodology. In 2006, further methodological changes were made to the sample design and automated occupation coding. These are the discontinuities shown above.

\section{Figure 11}

\section{Gender pay gap of full-time employees' average hourly pay: by age band, ${ }^{1} 2008$}

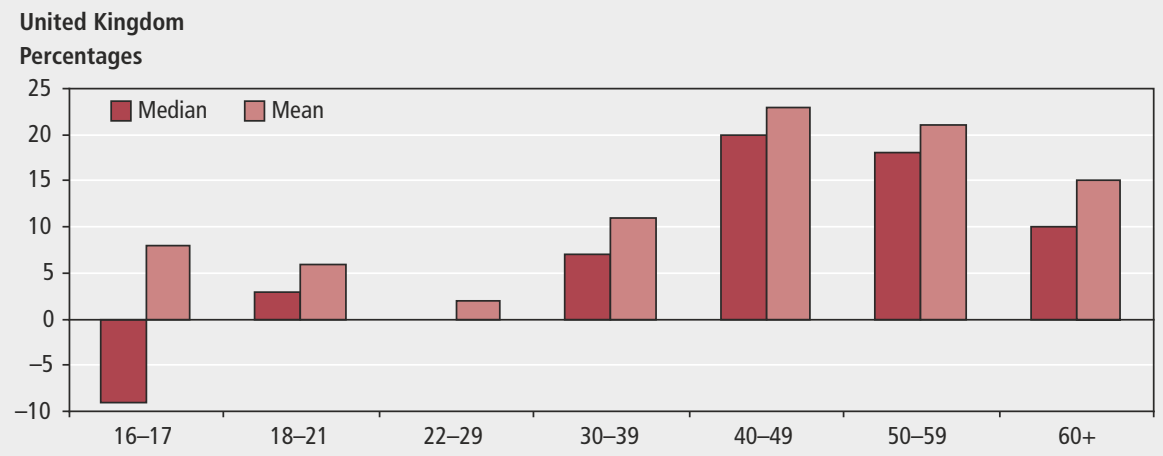

Note:

Source: Annual Survey of Hours and Earnings

1 Includes adult rates of pay (and junior rates of pay for 16 to 17-year-olds), excluding overtime and unaffected by absence.

different patterns of childcare for women and men.

The gender pay gap using ASHE (as measured by the median hourly pay of full-time employees, excluding overtime) widened between 2007 and 2008. The gap between women's and men's median hourly pay was 12.8 per cent, compared with the 12.5 per cent recorded in 2007 (Figure 10).

Using a measure based on mean earnings, women's average hourly pay (excluding overtime) was 17.1 per cent less than men's pay, a widening from the 2007 figure of 17.0 per cent.

Another alternative way of measuring the gender pay gap is for all employees rather than restricting it to those working fulltime only. On this basis, the gender pay gap between women's and men's median hourly pay grew from 21.9 per cent in 2007 to 22.5 per cent in 2008 .

Figure 11 represents the gender pay gap of full-time employees by age band. The estimates show that the gender pay gap is fairly small until the 30 to 39 age group. The gender pay gap increases to a peak for the 40 to 49 age group. Older women are more likely to have career breaks from paid work to care for children and other dependents. These breaks impact on women's level of work experience, which in turn can impact their pay rates.

There is a negative pay gap for those aged 16 to 17 based on median earnings, where women earn more than men in that age group (although the pay gap is reversed when mean earnings are used). This suggests that 16 and 17-year-old men's earnings are more diverse and some of them earn a lot more while women's earnings tend to be more grouped around a midpoint.

There is a very small gender pay gap for those aged 18 to 21 and 22 to 29 years. Based on median hourly earnings of fulltime employees, it is 3.1 per cent for the 18 to 21 years group and non-existent for those aged 22 to 29 years. The 22 to 29 age group has the smallest pay gap between men and women. The small gap for this group corresponds with the age people tend to finish higher education and have been in the workforce for a relatively short length of time. Figure 11 also shows that the largest pay gap of full-time employees in 2008 exists for those aged 40 to 49 , at 19.6 per cent for median earnings, using ASHE data. They are closely followed by those aged 50 to 59 , where the pay gap is 18.2 per cent, based on median earnings. The mean hourly earnings measure shows a slightly larger pay gap between men and women than the median earnings, across all age groups.

The Labour Force Survey (LFS) is another source of earnings data, which includes additional information and characteristics, of interest when analysing the gender pay gap. The LFS results shown in Table 1 are calculated from actual pay and hours including overtime for an individual's main job, restricted to those from age 16 to state pension age. In the LFS, whether a respondent is working full time is down to their own assessment of their job; it is not determined by the number of hours worked. The results shown from the LFS are for July to September 2008 .

\section{Family characteristics}

Table 1 shows that men and women who are not married or cohabiting have similar median hourly pay, $£ 9.20$ for men and $£ 9.50$ for women, resulting in a negative gender pay gap of 3.2 per cent. However, the gender pay gap for married/cohabiting couples is 16.3 per cent.

The gender pay gap is largest where two dependent children are present, with a pay gap of 21.6 per cent, followed very closely where four or more dependent children are present, with a pay gap of 21.1 per cent. In comparison, the gender pay gap is smallest where no dependent children are present. Full-time women without dependent children earn $£ 10.00$, compared with $£ 11.00$ for full-time men without dependent children, resulting in a gender pay gap of 9.1 per cent.

\section{Personal characteristics}

The hourly pay of full-time disabled women is $£ 9.40$ compared with $£ 10.30$ for full-time disabled men, resulting in a gender pay gap of 9.0 per cent. In comparison, the results for those who do not classify themselves as disabled show the hourly pay of a full-time women as $£ 10.10$, compared with $£ 11.70$ for full-time men, resulting in a gender pay gap of 13.4 per cent.

The gender pay gap of full-time employees varies considerably across ethnic group. The 
Table 1

\section{Gender pay gap of full-time employees' gross median hourly pay: by various characteristics, $2008^{1}$}

United Kingdom

\begin{tabular}{|c|c|c|c|c|}
\hline & \multicolumn{3}{|c|}{ Median hourly earnings (f) } & \multirow[t]{2}{*}{$\begin{array}{r}\text { Gender pay gap } \\
\text { (per cent) }\end{array}$} \\
\hline & Female & Male & Persons & \\
\hline \multicolumn{5}{|l|}{ Married/cohabiting } \\
\hline Married/cohabiting/civil partner & 10.4 & 12.5 & 11.7 & 16.3 \\
\hline Non-married & 9.5 & 9.2 & 9.3 & -3.2 \\
\hline \multicolumn{5}{|l|}{ Number of dependent children } \\
\hline No dependent children & 10.0 & 11.0 & 10.6 & 9.1 \\
\hline One dependent child & 9.6 & 11.6 & 10.8 & 16.5 \\
\hline Two dependent children & 10.9 & 13.9 & 12.8 & 21.6 \\
\hline Three dependent children & 11.3 & 12.5 & 12.2 & 9.9 \\
\hline Four or more dependent children & 8.0 & 10.1 & 10.1 & 21.1 \\
\hline \multicolumn{5}{|l|}{ Disability } \\
\hline Disabled & 9.4 & 10.3 & 9.9 & 9.0 \\
\hline Not disabled & 10.1 & 11.7 & 11.1 & 13.4 \\
\hline \multicolumn{5}{|l|}{ Ethnicity } \\
\hline White & 10.1 & 11.6 & 11.0 & 13.0 \\
\hline Mixed & 7.7 & 11.6 & 8.9 & 33.2 \\
\hline Asian/Asian British & 9.4 & 10.0 & 9.6 & 6.2 \\
\hline Black/Black British & 11.5 & 10.4 & 10.9 & -10.8 \\
\hline Other (including Chinese) & 11.1 & 11.1 & 11.1 & 0.5 \\
\hline \multicolumn{5}{|l|}{ Education } \\
\hline Degree or equivalent & 14.7 & 17.4 & 16.0 & 15.6 \\
\hline Higher education & 11.5 & 14.4 & 12.7 & 20.1 \\
\hline GCE A level or equivalent & 8.4 & 10.9 & 9.9 & 22.4 \\
\hline GCSE grades $\mathrm{A}-\mathrm{C}$ or equivalent & 8.3 & 9.4 & 8.9 & 11.7 \\
\hline Other qualifications & 8.0 & 8.6 & 8.5 & 7.5 \\
\hline No qualification & 6.5 & 8.2 & 7.6 & 20.7 \\
\hline
\end{tabular}

Note:

Source: Labour Force Survey, July to September 2008

1 Estimates are based on full-time employees from age 16 to state pension age.

widest pay gap is for the ethnicity group

'Mixed', at 33.2 per cent. 'Black or Black

British' women earn on average $£ 11.50$ per

hour while their male counterparts earn

$£ 10.40$ per hour, resulting in a negative

gender pay gap of 10.8 per cent.

\section{Educational attainment}

According to the LFS, the level of qualification obtained also has an impact on the gender pay gap. The widest gender pay gaps are for those educated to A level, at 22.4 per cent, closely followed by those with 'no qualification' and 'higher education', where the gender pay gap is 20.7 and 20.1 per cent, respectively. The gender pay gap of full-time employees is narrowest for those with 'other qualifications', at 7.5 per cent.

Overall, the analysis has shown there is a gender pay gap present, but the pay position of women working full-time has improved over time compared with that of full-time men. The gender pay gap does, however, vary depending on an individual's circumstances, for example, marital status and number of dependent children. For further information on the gender pay gap and characteristics of those who tend to be more affected by the gender pay gap, see Leaker (2008). Further analysis on the gender pay gap which takes account of some characteristics of employees is also available (Barnard 2008). This analysis demonstrated that even after controlling for some characteristics available from the ASHE dataset, there was still a gender pay gap present which cannot be explained.

\section{National Minimum Wage}

ASHE estimates for spring 2008 show that there were 288,000 jobs held by people aged 16 and over who were paid below the National Minimum Wage (NMW). This equates to 1.1 per cent of the number of UK jobs (see Table 2, overleaf). It is estimated that 17,000 (3.9 per cent of jobs held by employees in this age group) were held by people aged 16 and 17, 47,000 (2.6 per cent of jobs) by people aged 18 to 21 and 224,000 ( 0.9 per cent) by those aged 22 and over.
The percentage of jobs below the NMW in 2008 ( 1.1 per cent) was the same as in 2007 and slightly lower than in 2006 (1.2 per cent). In spring 2008, the NMW was $£ 3.40$ for those aged 16 and $17, £ 4.60$ for those aged between 18 and 21 and $£ 5.52$ for those aged 22 and over.

It should be noted that estimates of jobs paid below the NMW do not measure noncompliance with the NMW legislation. This is because the survey data used to provide the estimates do not indicate whether an individual is eligible for the minimum wage. For example, some people, such as apprentices or new trainees, are exempt from the minimum wage or are only entitled to lower rates. Also, if employees receive free accommodation, employers are entitled to offset hourly rates.

\section{CONTACT}

(지 elmr@ons.gsi.gov.uk

\section{REFERENCES}

Barnard A (2008) 'Modelling the gender pay gap in the UK: 1998 to 2006', Economic \& Labour Market Review 2(8) pp 18-24 and at www.statistics.gov.uk/cci/article. asp? id $=2032$

Leaker $D$ (2008) 'The gender pay gap in the UK', Economic \& Labour Market Review 2(4) pp 19-24 and at

www.statistics.gov.uk/cci/article. $a s p ? i d=1979$

Office for National Statistics Annual Survey of Hours and Earnings at

www.statistics.gov.uk/statbase/product. asp?vlnk=15187

Office for National Statistics Average Earnings Index at

www.statistics.gov.uk/statbase/tsdataset. asp?vInk=392

Office for National Statistics Average Weekly Earnings at

www.statistics.gov.uk/statbase/product. asp? vInk=14015

Office for National Statistics Index of Labour Costs per Hour at www.statistics.gov.uk/statbase/product. asp? vInk=14016

Office for National Statistics Labour Costs Survey at www.statistics.gov.uk/statbase/product. asp?vInk=10176

Office for National Statistics Retail Prices Index at www.statistics.gov.uk/statbase/tsdataset. asp?vlnk=229 
Table 2

Percentage of jobs and level of jobs paid below the National Minimum Wage ${ }^{1}$

United Kingdom

\begin{tabular}{|c|c|c|c|c|c|c|c|c|}
\hline & \multicolumn{4}{|c|}{ Percentage of jobs } & \multicolumn{4}{|c|}{ Level of jobs (thousands) } \\
\hline & \multicolumn{4}{|c|}{22 and } & & \multicolumn{3}{|c|}{22 and } \\
\hline & $16-17^{2}$ & $18-21$ & over & All jobs & $16-17^{2}$ & $18-21$ & over & All jobs \\
\hline $1998^{3,4}$ & - & 7.2 & 5.4 & 5.6 & - & 110 & 1,170 & 1,280 \\
\hline 1999 & - & 2.4 & 2.1 & 2.1 & - & 40 & 460 & 490 \\
\hline 2000 & - & 2.2 & 0.9 & 1.0 & - & 30 & 190 & 230 \\
\hline 2001 & - & 2.1 & 0.9 & 1.0 & - & 40 & 210 & 240 \\
\hline 2002 & - & 2.7 & 1.3 & 1.4 & - & 50 & 290 & 340 \\
\hline 2003 & - & 2.3 & 0.9 & 1.0 & - & 40 & 210 & 250 \\
\hline $2004^{5}$ & - & 2.3 & 1.0 & 1.1 & - & 44 & 233 & 276 \\
\hline 2005 & 4.0 & 3.0 & 1.0 & 1.2 & 20 & 55 & 233 & 308 \\
\hline 2006 & 3.8 & 2.3 & 1.0 & 1.2 & 14 & 44 & 238 & 296 \\
\hline 2007 & 4.0 & 2.6 & 1.0 & 1.1 & 16 & 49 & 231 & 296 \\
\hline 2008 & 3.9 & 2.6 & 0.9 & 1.1 & 17 & 47 & 224 & 288 \\
\hline
\end{tabular}

\section{Notes:}

Source: Labour Force Survey; Annual Survey of Hours and Earnings

1 Estimates are from spring each year.

2 The minimum wage for 16 and 17-year-olds was introduced in October 2004.

3 Estimates for 1998 to 2003 are based on a central estimate from both the Labour Force Survey and the Annual Survey of Hours and Earnings.

4 Figures for spring 1998, before the National Minimum Wage was introduced, are for the number of jobs paid at less than $\mathrm{f} 3.00$ per hour (aged 18 to 21 ) or $\mathrm{f} 3.60$ per hour (aged 22 and over).

5 A new methodology using only ASHE data was introduced in 2004. This improved coverage of the low end of the pay distribution and estimating the number of jobs below the National Minimum Wage. 